\title{
Phenotypic Characterization of Larval Zebrafish (Danio rerio) with Partial Knockdown of the cacna1a Gene
}

\author{
Kinga Gawel ${ }^{1,2}$ (D) $\cdot$ Waldemar A. Turski ${ }^{2}$ (D) $\cdot$ Wietske van der Ent $^{1}$ (D) $\cdot$ Benan J. Mathai $^{3}$ (D) \\ Karolina J. Kirstein-Smardzewska ${ }^{1}$ • Anne Simonsen ${ }^{3}$ (D) Camila V. Esguerra $^{1,4}$ (D)
}

Received: 16 August 2019 / Accepted: 15 December 2019 / Published online: 26 December 2019

(C) The Author(s) 2019

\begin{abstract}
The CACNA1A gene encodes the pore-forming $\alpha 1$ subunit of voltage-gated $\mathrm{P} / \mathrm{Q}$ type $\mathrm{Ca}^{2+}$ channels $\left(\mathrm{Ca}_{\mathrm{v}} 2.1\right)$. Mutations in this gene, among others, have been described in patients and rodents suffering from absence seizures and episodic ataxia type 2 with/ without concomitant seizures. In this study, we aimed for the first time to assess phenotypic and behavioral alterations in larval zebrafish with partial cacnalaa knockdown, placing special emphasis on changes in epileptiform-like electrographic discharges in larval brains. Whole-mount in situ hybridization analysis revealed expression of cacnalaa in the optic tectum and medulla oblongata of larval zebrafish at 4 and 5 days post-fertilization. Next, microinjection of two antisense morpholino oligomers (individually or in combination) targeting all splice variants of cacna laa into fertilized zebrafish eggs resulted in dose-dependent mortality and decreased or absent touch response. Over 90\% knockdown of cacnalaa on protein level induced epileptiform-like discharges in the optic tectum of larval zebrafish brains. Incubation of morphants with antiseizure drugs (sodium valproate, ethosuximide, lamotrigine, topiramate) significantly decreased the number and, in some cases, cumulative duration of epileptiform-like discharges. In this context, sodium valproate seemed to be the least effective. Carbamazepine did not affect the number and duration of epileptiform-like discharges. Altogether, our data indicate that cacnalaa loss-of-function zebrafish may be considered a new model of absence epilepsy and may prove useful both for the investigation of Cacnala-mediated epileptogenesis and for in vivo drug screening.
\end{abstract}

Keywords Zebrafish $\cdot C A C N A 1 A$ gene $\cdot$ Loss of function $\cdot$ Epilepsy $\cdot$ Touch response $\cdot$ Antiseizure drugs

Wietske van der Ent and Benan J. Mathai equally contributing authors

Electronic supplementary material The online version of this article (https://doi.org/10.1007/s12035-019-01860-x) contains supplementary material, which is available to authorized users.

Camila V. Esguerra

c.v.esguerra@ncmm.uio.no

1 Chemical Neuroscience Group, Centre for Molecular Medicine Norway, Faculty of Medicine, University of Oslo, Gaustadalléen 21, Forskningsparken, 0349 Oslo, Norway

2 Department of Experimental and Clinical Pharmacology, Medical University of Lublin, Jaczewskiego St. 8b, 20-090 Lublin, Poland

3 Faculty of Medicine, Institute of Basic Medical Sciences and Centre for Cancer Cell Reprogramming, Institute of Clinical Medicine, University of Oslo, 1112 Blindern, 0317 Oslo, Norway

4 School of Pharmacy, Faculty of Mathematics and Natural Sciences, University of Oslo, Sem Sælandsvei 24, 0371 Oslo, Norway

\section{Introduction}

CACNA1A encodes the pore-forming $\alpha 1$ subunit of voltagegated $\mathrm{P} / \mathrm{Q}$ type $\mathrm{Ca}^{2+}$ channels $\left(\mathrm{Ca}_{\mathrm{v}} 2.1\right)$ [1]. These channels are most abundantly located on presynaptic terminals, especially in Purkinje cells of the cerebellum where they control neurotransmitter release [2-5]. However, high expression of $\mathrm{P} / \mathrm{Q}$ calcium channels has also been found in the frontal cortex and the CA1 region of the hippocampus [2, 6], the brain structures involved in generation, maintenance and spread of discharges in generalized epilepsy [7]. Mutations in CACNA1A have been described in patients suffering from autosomaldominant diseases: familial hemiplegic migraine type 1, spinocerebellar ataxia type 6 , and episodic ataxia type 2 (reviewed by [8]).

Although the type of mutation in the CACNAIA gene determines, at least partially, the disease phenotype, mutation carriers still exhibit a diverse range of symptoms, which moderately overlap. It is believed that predominantly nonsense mutations or deletions of the gene determine the clinical 
manifestations in episodic ataxia type 2 patients $[9,10]$. However, missense mutations in CACNA1A resulting in loss of $\mathrm{P} / \mathrm{Q}$ type $\mathrm{Ca}^{2+}$ channel activity were described in infantile epilepsy with myoclonus [11]. Apart from recurrent ataxia, incoordination, slurring of speech, vertigo, and/or nystagmus, some patients present absence [12], myoclonic [13, 14], or febrile seizures [13, 15]. Moreover, early-onset epileptic encephalopathy has been described in humans $[9,10,16]$. Additionally, CACNA1A mutations have been detected in rodents [17-19] and humans suffering from absence seizures with/without cerebellar ataxia [13, 20, 21].

In the last decade, zebrafish (Danio rerio) has emerged as a new, attractive species for modeling human brain disorders. With regard to epilepsy research, the utility of zebrafish to mimic aspects of this human disorder has been demonstrated for Dravet syndrome (i.e., SCN1A mutations) [22, 23], pyridoxine-dependent epilepsy (ALDH7A1 and PLPBP) [24, 25], focal seizures (DEPDC5) [26], or in CHD2-mediated epileptic encephalopathies [27, 28]. More recently, Samarut et al. [29], using CRISPR/Cas9 technology, generated a new gabral $^{-/-}$mutant zebrafish line in order to unravel the epileptogenic mechanisms underlying gabral deficiency and this study undoubtedly confirmed the potential of zebrafish for elucidating mechanisms underlying the process of epileptogenesis. Additionally, drug screening in zebrafish larvae has also been performed in genetic epilepsy models. Baraban et al. [30] took advantage of the epileptic phenotype of scn $1 \mathrm{lab} \mathrm{b}^{-/-}$mutant zebrafish larvae and were able to identify clemizole as a potential new drug candidate by using a largescale screening program in scnllab ${ }^{-/-}$mutant zebrafish. Zhang et al. [22] demonstrated that another zebrafish model of Dravet syndrome responded to a drug lead in the same manner as human patients. They showed for the first time the anti-seizure effect of fenfluramine in scnllab knockdown zebrafish larvae. Interestingly, fenfluramine, which showed success in phase III trials for the management of Dravet syndrome, did not exhibit any activity in the equivalent rodent models, highlighting the utility of zebrafish for identifying and/or validating new drug leads. More recently, Sourbron et al. [31] performed a drug-repurposing screen, by assessing the response of scn $1 l a b^{-/-}$mutant larvae to three different drugs targeting the serotonergic system. In this preliminary study, lisuride (anti-parkinson's drug, 5- $\mathrm{HT}_{2 \mathrm{~A}}$, types 2 and 3 dopamine receptor agonist) emerged as a new drug candidate for Dravet syndrome patients.

With regard to developmental stages, 3-day post-fertilization (dpf) in zebrafish (i.e., day of hatching) corresponds to the time of human birth, while every successive day thereafter corresponds to 3 months of age in humans (i.e., 4, 5, 6, and $7 \mathrm{dpf}$ are the equivalent to $3,6,9$, and 12 months of age in children, respectively). The zebrafish is also a favorable alternative to rodents in the context of genetic manipulation (described in detail by [32]). The zebrafish genome has been fully sequenced and annotated and exhibits approximately $70 \%$ similarity with the human genome [33]. Of note, during the process of evolution, some genes were duplicated in zebrafish [34]. The cacnala gene in zebrafish is duplicated, with $72.01 \%$ (cacnalaa) and $71.28 \%$ (cacnalab) homology with human CACNA1A (https://zfin.org/), the former having three splice variants in zebrafish.

Although, there are good models of absence epilepsy in rodents, including the well-established and pharmacologically validated GAERS and WAG/Rij rats, spike-wave discharges in these models start appearing relatively late during development (2-3 months of age, which corresponds to the juvenile stage in humans). This is not consistent with the fact that absence epilepsy in humans typically manifests itself early during development (childhood). Moreover, although WAG/ Rij rats exhibit absence seizures, the mutation leading to the epilepsy phenotype has not been identified to date [35]. In case of GAERS rats, it is believed that mutations in Cacnalh lead to epilepsy [36]. In this context, the zebrafish model of absence epilepsy may offer another advantage. Thus, in this study, we aimed for the first time to assess whether larval zebrafish may suffer from cacnala-mediated absence seizures. Given that there is a lack of data about cacnlaarelated zebrafish phenotypes, we therefore aimed to describe all phenotypic defects in this study. Toward this end, we first assessed the expression of cacnalaa in the larval zebrafish brain using in situ hybridization analysis. Next, the combination of two antisense morpholino oligomers (MOs) targeting ATG codons of all splice variants was used to achieve partial knockdown of cacnalaa. Using this approach, we assessed whether the partial loss-of-function (LOF) of cacnalaa could induce an epileptic-like phenotype in larval zebrafish, both on the behavioral and electroencephalographic (EEG) levels. To further examine the character of cacnalaa epileptiform-like discharges, we assessed the activity of four antiseizure drugs (ASDs) effective in the treatment of human absence seizures (i.e., sodium valproate (VPA), ethosuximide (ETX), lamotrigine (LTG), and topiramate (TPR)) and one drug (i.e., carbamazepine (CBZ)) that is contraindicated for this type of seizure.

\section{Materials and Methods}

\section{Zebrafish Maintenance}

Adult zebrafish (Danio rerio) stocks of the AB strain (kind gift from Ana Carolina Sulen Tavara, Norwegian University of Life Sciences, Oslo, Norway) were maintained at standard aquaculture conditions (i.e., $28.5^{\circ} \mathrm{C}, 14 / 10 \mathrm{~h}$ light/dark cycle). Fertilized eggs were collected via natural spawning. Embryos were reared under constant light conditions in embryo medium, i.e., Danieau's buffer: 1.5-mM Hepes, pH 7.6, 17.4-mM 
$\mathrm{NaCl}, 0.21-\mathrm{mM} \mathrm{KCl}, 0.12-\mathrm{mM} \mathrm{MgSO}_{4}$, and $0.18-\mathrm{mM}$ $\mathrm{Ca}\left(\mathrm{NO}_{3}\right)_{2}$. All embryos and larvae were kept in an incubator, at $28.5^{\circ} \mathrm{C}$. All experimental protocols and housing conditions were carried out according to the National Institute of Health Guidelines for the Care and Use of Laboratory Animals, the European Community Council Directive of November 2010 for Care and Use of Laboratory Animals (Directive 2010/63/ EU), and the ARRIVE guidelines. All experiments were approved by the Norwegian Food Safety Authority experimental animal administration's supervisory and application system (FOTS-18/106800-1).

\section{Drugs}

The following ASDs were used: CBZ $(100 \mu \mathrm{M})$, ETX $(10 \mathrm{mM})$, LTG $(200 \mu \mathrm{M})$, TPR $(100 \mu \mathrm{M})$, and VPA $(100 \mu \mathrm{M})$. All drugs, except for VPA (Sanofi Aventis), were purchased from Sigma-Aldrich. The doses of drugs were chosen on the basis of previous literature [22,37] and preliminary tests. All ASDs were dissolved in DMSO and diluted in embryo medium to achieve a final concentration of DMSO of $0.5 \% \mathrm{v} / \mathrm{v}$. Embryo medium, prepared with DMSO in a final concentration of $0.5 \% \mathrm{v} / \mathrm{v}$, served as a vehicle (Veh).

\section{Whole-Mount In Situ Hybridization}

Whole-mount in situ hybridization analysis for cacnalaa was performed as previously described [38] using digoxigeninlabeled riboprobes. Primer sequences for cacnalaa sense and antisense probes are plotted in Table 1. Embryos were fixed at 4 or $5 \mathrm{dpf}$ in $4 \%$ paraformaldehyde in $1 \times$ PBS. Digoxigenin (DIG) UTP-labeled RNA riboprobes were made from linearized constructs using the mMESSAGE mMACHINETM SP6 Transcription Kit, mMESSAGE mMACHINETM T7 Transcription Kit (Thermo Scientific Fisher), and DIG RNA labeling Mix (Roche). Sense and antisense RNA probe-stained $4 \mathrm{dpf}$ and $5 \mathrm{dpf}$ larvae were imaged on a Stemi 508 DOC Zeiss stereomicroscope with mounted axiocam color camera. The experiment was replicated twice, with $n=6-8 /$ group.

\section{Microinjection of Antisense MOs}

Antisense MOs were designed and synthesized by Gene Tools, LLC (Philomath, OR, USA). The sequences of MO were plotted in Table 1. The targets for partial knockdown were ATG codons of cacnalaa transcripts, i.e., cacnalaa201 and cacnalaa-202 \& cacnalaa-203, herein referred to as MO1 and MO2, respectively. A random sequence standard control MO (Ctrl-MO) and p53 MO (4 ng), suppressing p53 mRNA, were used to assess the specificity of the observed phenotype. All MOs, individually or in combination, were injected into the yolk of one- or two-cell stage embryos, in a total volume of $1.5 \mathrm{nl} / \mathrm{embryo}$.

\section{Western Blot Analysis}

The anti-CACNA1A antibody was generated using a synthetic peptide from human CACNA1A amino acids 2050-2150. Using Clustal Omega, alignment of this region showed $89 \%$ and $50 \%$ homology between human CACNA1A and zebrafish cacnalaa and human CACNA1A and zebrafish cacnalab, respectively.

Four-day-old Ctrl-MO and cacnalaa morphants were collected (25 larvae/sample, $n=3-4$ /group), placed in $100 \mu$ of RIPA buffer (Sigma Aldrich), immediately boiled at $95^{\circ} \mathrm{C}$ for $10 \mathrm{~min}$ and kept at $-80^{\circ} \mathrm{C}$ until further analysis. Total protein was separated on a $12 \%$ SDS-polyacrylamide gel and transferred electrophoretically to a nitrocellulose membrane. Next, the membrane was blocked for $1 \mathrm{~h}$ with $5 \%$ skim milk (SigmaAldrich, USA) in PBS containing 0.1\% Tween-20 and again incubated overnight with rabbit monoclonal anti-CACNA1A antibody (ab181371, 1:2000; Abcam) or rabbit monoclonal anti- $\beta$-actin antibody (ab8226, 1:2000; Abcam) that served as primary antibodies. Goat anti-rabbit (31460, 1:2500; Thermo Fisher) horseradish peroxidase-conjugated secondary antibody was used to detect the primary antibodies, and the
Table 1 Sequences of antisense MOs and primer sequences for cacnalaa sense and antisense probes

\begin{tabular}{ccc}
\hline $\begin{array}{l}\text { Morpholino } \\
\text { name }\end{array}$ & Morpholino sequence & Primer sequences for probes \\
\hline cacnalaa MO1 & 5'-TGTACTCAAATGGAGTGAGA & f: 5'CCTTGACCTATGATTCTCAC \\
& ATCAT-3' & TCC3' \\
cacnalaa MO2 & 5'-TCATCTCCGAACCGAGCCAT & r: 5CACTCCCTGCAGCATCATT \\
& TCTAT-3' & \\
Ctrl-MO & 5'-CCTCTTACCTCAGTTACAAT \\
p53 MO & T'-GCGCA-3' \\
& -3' \\
\hline
\end{tabular}

$f$, forward; $r$, reverse 
resulting signal was measured with the SIGMAFAST ${ }^{\text {TM }}$ DAB with Metal Enhancer (SLBP7387V; Sigma Aldrich). Prestained molecular weight protein marker (Presicion Plus Protein $^{\mathrm{TM}}$ Dual Color Standars; Bio-Rad) was used to determine the molecular weight of each detected band and to confirm antibody target specificity. Total protein level was normalized relative to $\beta$-actin protein level.

\section{Morphological Phenotyping}

Mortality of eggs and larvae injected with Ctrl-MO and cacna la a MO (individually and in combination) was assessed $4 \mathrm{~h}$ post-fertilization (hpf) and $24 \mathrm{hpf}$. Larvae were visually inspected for severe malformations (e.g., pericardial edema, body axis curvature, hemorrhage) from 1 to $5 \mathrm{dpf}$. For documentation, cacnalaa and Ctrl-MO morphants were photographed at $4 \mathrm{dpf}$, using a Leica MZ10F stereomicroscope equipped with a DFC310 FX digital camera.

\section{Touch-Evoked Response}

At 4 dpf, the touch-evoked response was evaluated in 48-well plates. Larvae were lightly touched on the tail with the tip of metal tweezers and their response was scored as follows: (1) "absent" - the larva does not move at all after several tactile stimuli given, (2) "decreased"- the larva performs a movement after several stimuli, (3) "normal"- the larva moves immediately after a single stimulus.

\section{Locomotor Activity}

At 4 dpf, cacnlaa morphants as well as Ctrl-MO zebrafish larvae were placed in a 48-well plate (one larva per well) filled with $300 \mu \mathrm{l}$ of embryo medium, and habituated to the automated tracking device (ZebraBox, Viewpoint, Lyon, France) for $10 \mathrm{~min}$ in light, followed by $10 \mathrm{~min}$ in dark phase. Subsequently, the distance covered in millimeters by each larva was recorded for a total period of $10 \mathrm{~min}$, with the following intervals: (1) $5 \mathrm{~min}$ in light phase and (2) $5 \mathrm{~min}$ in dark phase. Two independent experiments were done, and the data were pooled together.

\section{EEG Analysis}

In order to detect epileptiform-like discharges in zebrafish larvae, the EEG recordings were conducted according to the method described previously [39]. The EEG recordings were obtained from zebrafish larval optic tectum at $4 \mathrm{dpf}$. Larvae were immobilized in a thin layer of $2 \%$ low-melting-point agarose, and the glass electrode (resistance 1-5 M $\Omega$ ) filled with artificial cerebrospinal fluid (124 mM NaCl, $2 \mathrm{mM}$ $\mathrm{KCl}, 2 \mathrm{mM} \mathrm{MgSO} 4,2 \mathrm{Mm} \mathrm{CaCl}_{2}, 1.25 \mathrm{mM} \mathrm{KH}_{2} \mathrm{PO}_{4}$, $26 \mathrm{mM} \mathrm{NaHCO}, 10 \mathrm{mM}$ glucose) was placed into the optic tectum (MultiClamp 700B amplifier, Digidata 1550 digitizer, Axon instruments, USA). Single recordings for each larva were performed for a period of $20 \mathrm{~min}$. The threshold for detection of epileptiform-like discharges was set at $3 \times$ background noise and $150 \mathrm{~ms}$. The data were analyzed with the aid of the Clampfit 10.2 software (Molecular Devices Corporation, USA) and custom-written R script for Windows.

\section{Effect of ASDs on EEG}

Freely swimming $4 \mathrm{dpf}$ Ctrl-MO and cacnalaa morphants were incubated with ASDs or Veh, within $2 \mathrm{~h}$ before EEG analysis. EEG recordings were conducted as described above. Number of epileptiform-like discharges, cumulative duration of events, and mean duration of events were determined.

\section{Statistical Analysis}

Mortality and touch-evoked response were analyzed using two-sided Fisher's exact test. Locomotor activity and EEG data were analyzed by one-way analysis of variance (ANOVA), followed by Tukey's post-hoc test. $P$ values less than 0.05 were considered statistically significant. For a purpose of statistical analysis, GraphPad Prism 7.05 version (San Diego, CA, USA) was used. For figures generation, GraphPad Prism 7.05 or ImageJ (https://imagej.nih.gov/ij/) were used.

\section{Results}

\section{Expression Pattern of cacna1aa in the Brain}

Since the expression of cacnalaa was previously described by Thisse and Thisse [38] during early stages of zebrafish development, we focused on analyzing cacnalaa mRNA expression at the stages when behavioral and EEG experiments were performed. Both dorsal and lateral views of the head, in whole-mount in situ hybridization, for wild type 4 and $5 \mathrm{dpf}$ zebrafish revealed prominent cacnalaa mRNA expression in the midbrain and hindbrain, but low expression in the forebrain and retina (Fig. 1). High expression of cacna la a mRNA at $4 \mathrm{dpf}$ larvae was detected in the optic tectum and even higher expression in the medulla oblongata. The staining was even more pronounced at $5 \mathrm{dpf}$. No detectable expression was observed in $5 \mathrm{dpf}$ sense control larvae (Fig. 1).

\section{Mortality Rate and Touch Response of cacna1aa Morphants}

Microinjected Ctrl-MO affected neither mortality rate of embryos and larvae, assessed at $4 \mathrm{hpf}$ and $24 \mathrm{hpf}$, nor larval touch response as determined at $4 \mathrm{dpf}$ (Tables 2 and 3 ). 
Administration of cacnalaa $\mathrm{MO} 1$ at $7.5 \mathrm{ng}$ also did not affect mortality rate of embryos and larvae as well, but a higher dose of $9 \mathrm{ng}$ significantly enhanced mortality $(P<$ 0.05). Similarly, a second MO, cacnalaa MO2, did not influence mortality at both tested time points at the same dose of $9 \mathrm{ng}$, but slightly increased mortality of embryos and larvae at $12 \mathrm{ng}$ by $4 \mathrm{hpf}(P<0.05)$. Simultaneous administration of cacnalaa $\mathrm{MO} 1+\mathrm{MO} 2$ at combined doses of $2.5 \mathrm{ng}+$ $2.5 \mathrm{ng}$ resulted in no increase in mortality. However, a significant increase in mortality to $60 \%$ was evoked by simultaneous administration of cacnalaa $\mathrm{MO} 1+\mathrm{MO} 2$ at combined doses of $4.5 \mathrm{ng}+4.5 \mathrm{ng}$ after $24 \mathrm{hpf}$ (Table 2).

With regard to larval touch response, administration of cacnalaa $\mathrm{MO} 1$ at tested doses of $7.5 \mathrm{ng}$ and $9 \mathrm{ng}$ or of cacnalaa MO2 at doses of $9 \mathrm{ng}$ and $12 \mathrm{ng}$ hampered larval touch response significantly. Simultaneous administration of cacnalaa $\mathrm{MO} 1+\mathrm{MO} 2$ at doses of $2.5 \mathrm{ng}+2.5 \mathrm{ng}$ did not influence touch response, whereas combined doses of $4.5 \mathrm{ng}+$ $4.5 \mathrm{ng}$ resulted in a moderate decrease in the touch-evoked response (Table 3).

Based on these results, the simultaneous administration of cacnalaa $\mathrm{MO} 1+\mathrm{MO} 2$ at doses of $2.5 \mathrm{ng}+2.5 \mathrm{ng}$ was chosen for further experiments. The western blot analysis revealed that these doses reduced cacnlaa protein levels to $10 \%$ relative to the control (Fig. 2a and Supp. Fig 1).

\section{Morphological and Behavioral Assessment of cacna1aa Morphants}

Visual inspection of cacnalaa morphants ( 9 or $12 \mathrm{ng}$, single dose) that survived until $4 \mathrm{dpf}$ revealed profound morphological malformations (curved body axis, small heads, tiny eyes, pericardial edema, yolk sac malformations) (data not shown). On the other hand, visual inspection of cacnala a morphants (doses $2.5 \mathrm{ng}+2.5 \mathrm{ng}$ ) revealed that at 4 and $5 \mathrm{dpf}$, larvae were slightly hyperpigmented in comparison with Ctrl-MO counterparts (Fig. 2b). In addition, at $4 \mathrm{dpf}$, the majority of cacnalaa morphant larvae (i.e., $84.4 \%(38 / 45)$ vs. $4.2 \%$ $(1 / 24)$ of Ctrl-MO injected larvae) did not inflate their swim bladder (see Fig. 2b). Measurements taken at $4 \mathrm{dpf}$ revealed that cacna laa morphants had a shorter body length $(P<0.05)$ compared with Ctrl-MO larvae ( $3.51 \mathrm{~mm} \pm 0.15, n=11$ vs $3.73 \mathrm{~mm} \pm 0.12, n=9$, respectively) (data not shown). There were no observable signs of necrosis, hemorrhage, pericardial edema, or axis truncation. The simultaneous administration of cacnalaa MOs and p53 MO (4 ng) indicated that the observed morphological changes were likely specific to cacnalaa partial knockdown and not due to off-target effects of the MO itself (see Supp. Fig 2).

To investigate the impact of partial cacnalaa LOF on behavior, larval locomotor activity of cacnalaa morphants
Fig. 1 Representative wild type larva in situ hybridization with cacnalaa antisense and sense probes. Dpf, days postfertilization; $\mathrm{MeO}$, medulla oblongata; $\mathrm{TeO}$, optic tectum

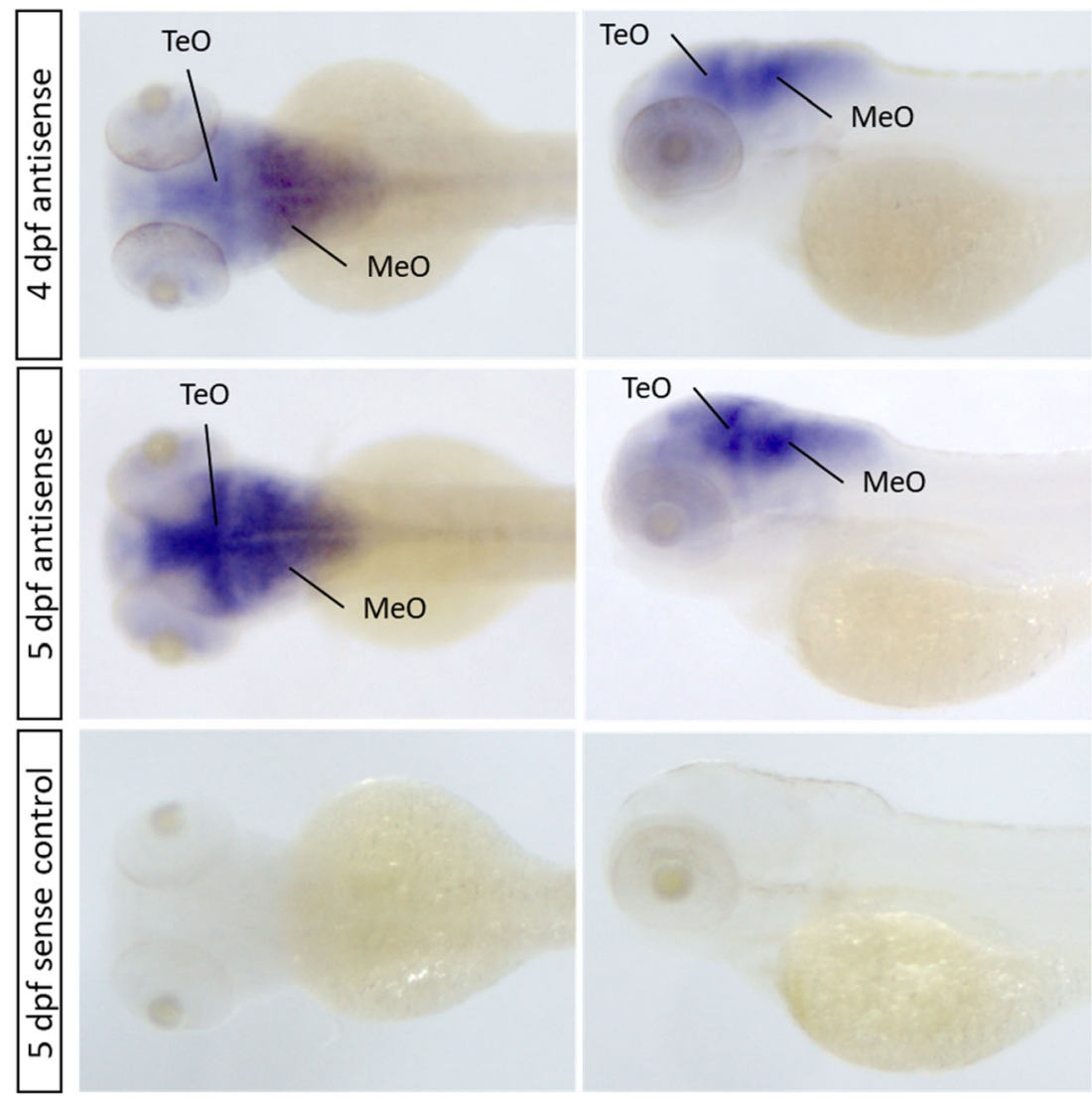


Table 2 Mortality of zebrafish cacnalaa knockdown larvae

\begin{tabular}{|c|c|c|c|}
\hline Treatment & Dose & $\begin{array}{l}\text { Death after } 4 \mathrm{hpf}(\%) \\
(\mathrm{n} / \mathrm{N})\end{array}$ & $\begin{array}{l}\text { Death after } 24 \mathrm{hpf}(\%) \\
(\mathrm{n} / \mathrm{N})\end{array}$ \\
\hline \multirow[t]{2}{*}{ Wild type } & Uninjected & 5.29 & 7.20 \\
\hline & & $(25 / 472)$ & $(34 / 472)$ \\
\hline \multirow[t]{2}{*}{ Ctrl-MO } & $5 \mathrm{ng}$ & 2.63 & 7.89 \\
\hline & & $(4 / 152)$ & $(12 / 152)$ \\
\hline \multirow[t]{4}{*}{ cacnalaa MO1 } & $7.5 \mathrm{ng}$ & 4.33 & 11.41 \\
\hline & & $(11 / 254)$ & $(29 / 254)$ \\
\hline & $9 \mathrm{ng}$ & $9.39 *$ & $43.19 *$ \\
\hline & & $(20 / 213)$ & $(92 / 213)$ \\
\hline \multirow[t]{4}{*}{ cacnalaa $\mathrm{MO} 2$} & $9 \mathrm{ng}$ & 4.69 & $11.18 \%$ \\
\hline & & $(21 / 447)$ & $(50 / 447)$ \\
\hline & $12 \mathrm{ng}$ & $10.56^{*}$ & 12.19 \\
\hline & & $(13 / 123)$ & $(15 / 123)$ \\
\hline \multirow[t]{4}{*}{ cacnalaa $\mathrm{MO} 1+\mathrm{MO} 2$} & $2.5 \mathrm{ng}+2.5 \mathrm{ng}$ & 4.14 & 8.03 \\
\hline & & $(16 / 386)$ & $(31 / 386)$ \\
\hline & $4.5 \mathrm{ng}+4.5 \mathrm{ng}$ & 4.69 & $60.40 *$ \\
\hline & & $(7 / 149)$ & $(90 / 149)$ \\
\hline
\end{tabular}

$n$, number of dead larvae; $N$, total number of larvae; $H p f$, hours post-fertilization Statistical analysis was performed using two-sided Fisher's exact test $* P<0.05$ vs respective Ctrl-MO group and Ctrl-MO was evaluated at 4 dpf. One-way ANOVA revealed a statistically significant differences between groups of animals $(\mathrm{F}(3,180)=21.84, P<0.05, n=44-48$ /group; Fig. 3$)$. We observed that the switch from light to dark phase increased activity of Ctrl-MO $(P<0.05)$. However, reduced locomotor activity was observed in cacnalaa morphants when compared with Ctrl-MO siblings in both analyzed phases (Light: $P<0$. 05, Dark: $P<0.05$; Fig. 3). Rapid switching from light to dark phase did not increase locomotor activity of morphants $(P>0$. $05)$.
Table 3 Touch-evoked response of zebrafish cacnalaa knockdown larvae

\begin{tabular}{|c|c|c|c|c|}
\hline Treatment & Dose & $\begin{array}{l}\text { Normal }(\%) \\
(\mathrm{n} / \mathrm{N})\end{array}$ & $\begin{array}{l}\text { Decreased (\%) } \\
(\mathrm{n} / \mathrm{N})\end{array}$ & $\begin{array}{l}\text { Absent }(\%) \\
(\mathrm{n} / \mathrm{N})\end{array}$ \\
\hline \multirow[t]{2}{*}{ Wild type } & Uninjected & 97.22 & 2.78 & 0 \\
\hline & & $(35 / 36)$ & $(1 / 36)$ & $(0 / 36)$ \\
\hline \multirow[t]{2}{*}{ Ctrl-MO } & $5 \mathrm{ng}$ & 98.07 & 1.92 & 0 \\
\hline & & $(51 / 52)$ & $(1 / 52)$ & $(0 / 52)$ \\
\hline \multirow[t]{4}{*}{ cacnalaa MO1 } & $7.5 \mathrm{ng}$ & $73.37 *$ & $18.51^{*}$ & $11.11 *$ \\
\hline & & $(38 / 54)$ & $(10 / 54)$ & $(6 / 54)$ \\
\hline & $9 \mathrm{ng}$ & $0^{*}$ & $16.66^{*}$ & $83.33 *$ \\
\hline & & $(0 / 24)$ & $(4 / 24)$ & $(20 / 24)$ \\
\hline \multirow[t]{4}{*}{ cacnalaa $\mathrm{MO} 2$} & $9 \mathrm{ng}$ & $52 *$ & $13.79 *$ & $36.20 *$ \\
\hline & & $(29 / 58)$ & $(8 / 58)$ & $(21 / 58)$ \\
\hline & $12 \mathrm{ng}$ & $0 *$ & 5.71 & $94.28 *$ \\
\hline & & $(0 / 35)$ & $(2 / 35)$ & $(33 / 35)$ \\
\hline \multirow[t]{4}{*}{ cacnalaa $\mathrm{MO} 1+\mathrm{MO} 2$} & $2.5 \mathrm{ng}+2.5 \mathrm{ng}$ & 96.82 & 3.17 & 0 \\
\hline & & $(61 / 63)$ & $(2 / 63)$ & $(0 / 63)$ \\
\hline & $4.5 \mathrm{ng}+4.5 \mathrm{ng}$ & $50^{*}$ & $20.83 *$ & $29.16^{*}$ \\
\hline & & $(12 / 24)$ & $(5 / 24)$ & $(7 / 24)$ \\
\hline
\end{tabular}

$n$, number of animals with a defined (i.e., absent, decreased, or normal) response; $N$, total number of animals Statistical analysis was performed using two-sided Fisher's exact test $* P<0.05$ vs respective Ctrl-MO group 
Fig. 2 a Representative western blot of $4 \mathrm{dpf}$ cacnalaa and CtrlMO larvae (left panel) and quantification of all samples (right panel). b Dorsal and side views of representative 4 dpf Ctrl-MO and cacnalaa MOs larvae a

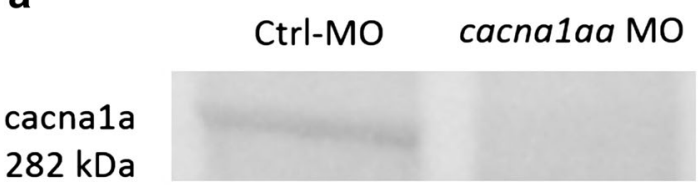

$282 \mathrm{kDa}$
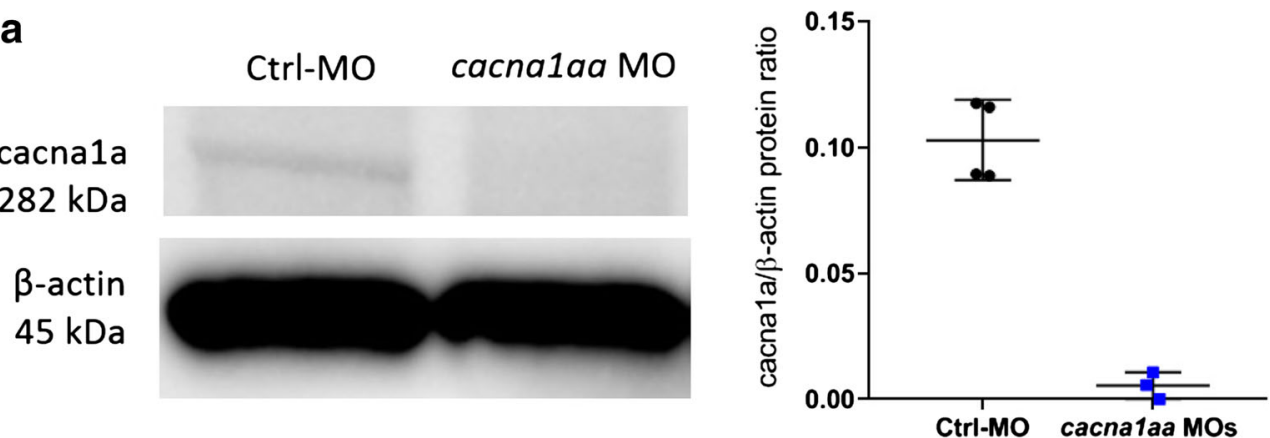

b
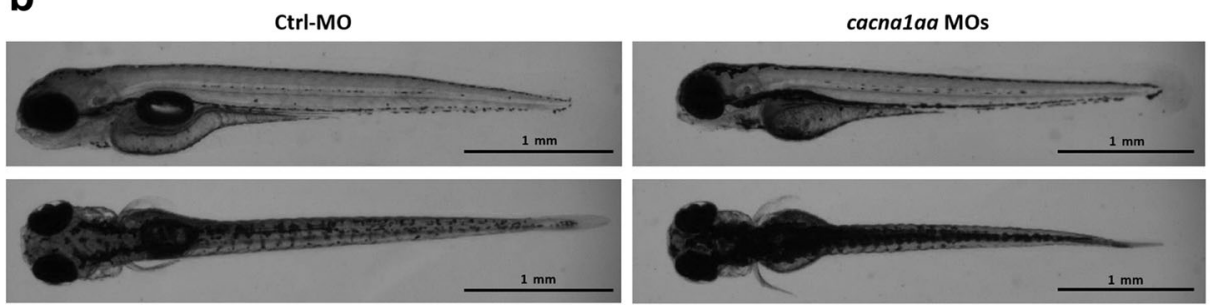

\section{Assessment of EEG Discharges in cacna1aa Morphants and Ctrl-MO Larvae and Effect of ASDs}

In 2 out of 19 (10.5\%) control morphants, single shortduration epileptiform-like events were observed (Fig. 4a). Spontaneous epileptiform-like events in the form of abrupt high-voltage spikes, spike-wave complexes, and polyspike-wave discharges (Fig. 4b-f) occurred in 24 out of $26(92 \%)$ cacnalaa morphants. In seizurepositive cacnalaa morphants, a mean frequency of events was 7 events/20-min recording, compared with 0.5 events/ 20-min recording in Ctrl-MO counterparts (Fig. 5a). In cacnalaa morphants, the mean and cumulative duration of EEG discharges was 503 and $3164 \mathrm{~ms} / 20 \mathrm{~min}$, respectively (Fig. 5b-c). One-way ANOVA revealed statistically significant differences between the tested groups in the number of epileptiform-like discharges $(\mathrm{F}(6.94)=9.16$, $P<0.05 ; n=9-25 /$ group; Fig. 5a), mean duration of events $(\mathrm{F}(6.94)=5.64, P<0.05 ; n=9-25 /$ group; Fig. $5 b)$, and cumulative duration of events $(\mathrm{F}(6.94)=9.17$, $P<0.05 ; n=9-25$ /group; Fig. 5c).

Tukey's post-hoc test revealed that 2-h incubation of cacnalaa morphants with ASDs indicated for the treatment of absence seizure in humans prior to EEG assessment decreased the number of epileptiform-like discharges substantially, compared with cacnalaa morphants incubated with Veh (Fig. 5a). Herein, VPA, ETX, LTG, and TPR were equally potent $(P<0.05)$. However, analysis of mean and cumulative duration of events revealed that ETX and TPR were the most effective in decreasing the duration of these parameters, when compared with Veh-treated cacnalaa morphants $(P<0.05$; Fig. $5 \mathrm{~b}$ and c). LTG tended to decrease mean duration of events
$(P>0.05$; Fig. $5 \mathrm{~b})$ and decrease the cumulative duration of events $(P<0.05$; Fig. $5 \mathrm{c})$. Differently, VPA tended to increase the mean duration of events $(P>0.05$; Fig. 5b) while decreasing cumulative duration of events, but results did not reach statistical significance $(P>0.05$; Fig. $5 \mathrm{c})$. CBZ, which is contraindicated in human patients with absence seizures, did not decrease any of the parameters when compared with cacnalaa morphants incubated with Veh $(P>0.05$; Fig. 5a-c). Incubation of Ctrl-MO larvae with all ASDs did not induce any changes in their EEG

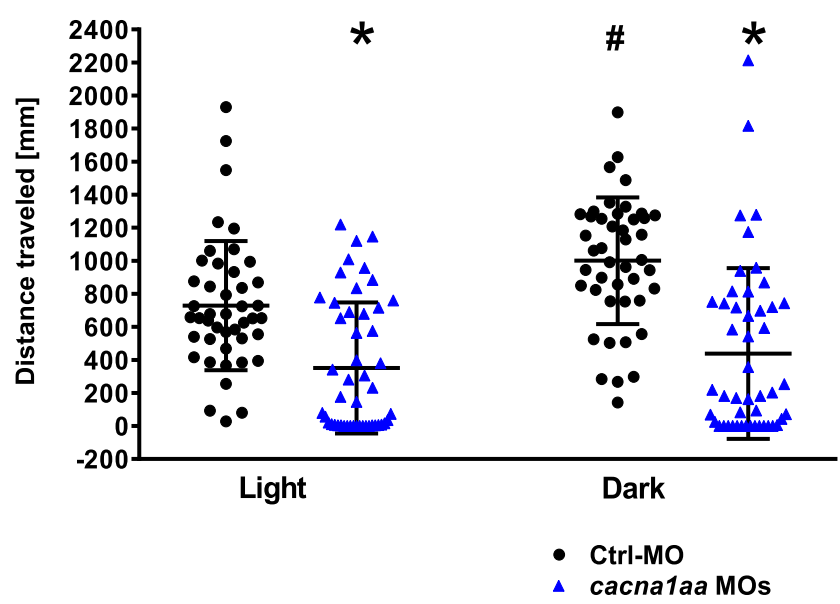

Fig. 3 Locomotor activity of $4 \mathrm{dpf}$ cacna laa and Ctrl-MO larvae. Larvae were habituated to the apparatus $20 \mathrm{~min}$ (10 min light, $10 \mathrm{~min}$ in dark) before experiment, and total locomotor activity was tracked within $10 \mathrm{~min}$. The data were pooled from 2 independent experiments. The results were analyzed using one-way ANOVA, followed by Tukey's post-hoc test. Dots represent individual measurements, the central horizontal mark is the mean, and error bars represent standard deviation (SD) ( $n=44-48 /$ group). ${ }^{*} P<0.05$ vs Ctrl-MO group in relevant phase, ${ }^{\#} P<0.05$ vs Ctrl-MO group in light phase. Dpf, days post-fertilization 
A

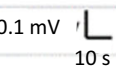

B

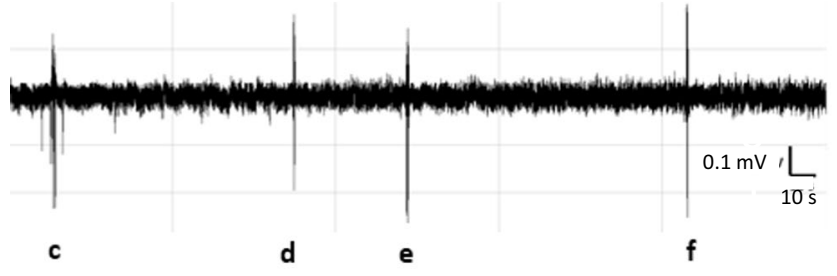

C

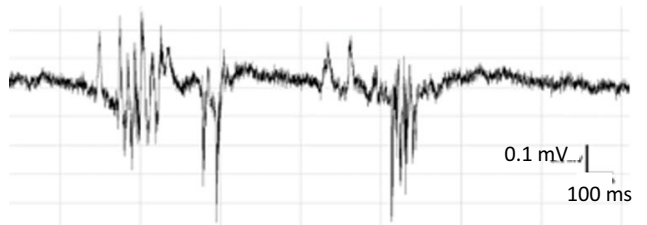

D

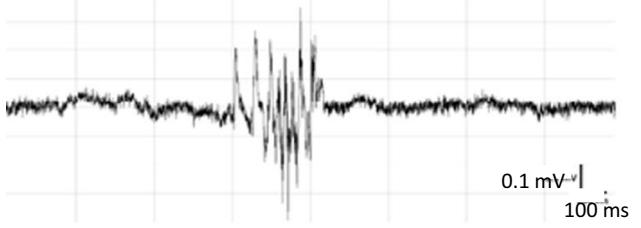

$\mathbf{E}$

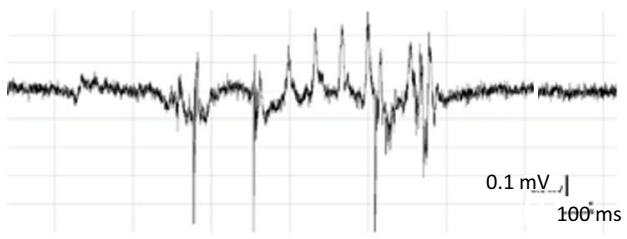

F

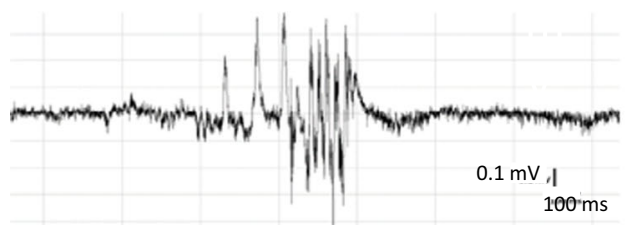

Fig. 4 Representative electroencephalographic recording illustrating the epileptiform-like discharges recorded in zebrafish Ctrl-MO larvae and cacnal aa morphants $(2.5 \mathrm{ng}+2.5 \mathrm{ng})$. The EEG recordings were obtained from zebrafish larval optic tectum at $4 \mathrm{dpf}$. a Five-minute-long fragment of representative recording from Ctrl-MO larvae. b Five-minute lasting continuous recording from cacnalaa morphant demonstrating the background and ictal activity. Small letters (c-f) correspond to respective ictal events depicted on traces $\mathbf{b}-\mathbf{e}$. $\mathbf{c}-\mathbf{f}$ Epileptiform-like discharges, high-voltage spikes, spike-wave complexes, and polyspike-wave discharges
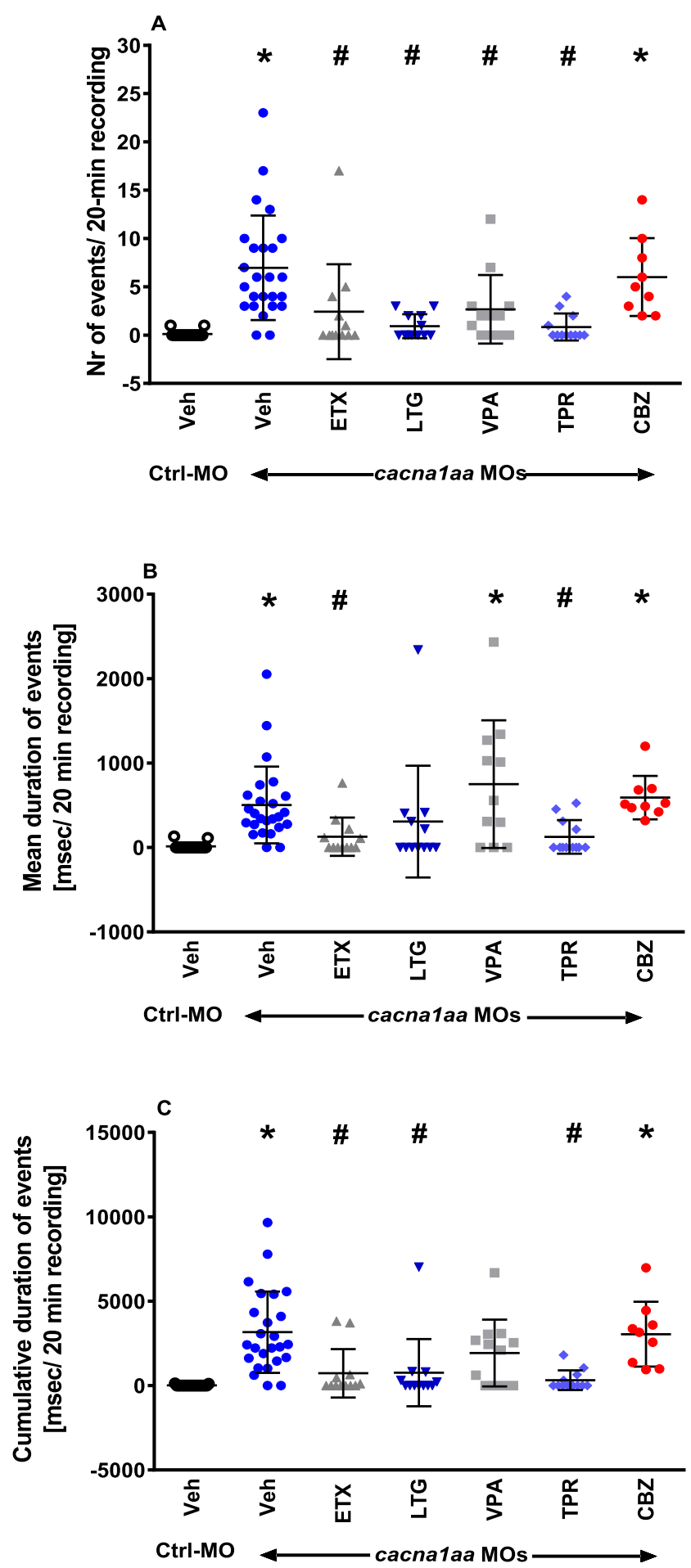

activity, compared with Ctrl-MO larvae incubated with Veh only $(P>0.05 ; n=7-25$; Supp. Fig 3 A-C).

\section{Discussion}

Our study revealed that partial cacnalaa LOF in larval zebrafish results in profound behavioral impairment and 
4 Fig. 5 Effect of ASDs on epileptiform-like discharges recorded from the optic tectum of $4 \mathrm{dpf}$ cacnalaa and Ctrl-MO morphants. Larvae were incubated $(2 \mathrm{~h})$ with different ASDs. Results are presented as a number of events, $\mathbf{b}$ mean duration of events (msec), and $\mathbf{c}$ cumulative duration of events (msec) during 20 min of recording. Statistical analysis was performed using one-way ANOVA with Tukey's post-hoc test. Dots represent individual measurements, the central horizontal mark is the mean, and error bars represent SD $(n=9-25)$. Symbols represent following comparisons: $* P<0.05$ vs Ctrl-MO group incubated with Veh, ${ }^{\#} P<0.05$ vs cacnalaa MOs group incubated with Veh. CBZ, carbamazepine $(100 \mu \mathrm{M})$; ETX, ethosuximide $(10 \mathrm{mM})$, LTG, lamotrigine $(200 \mu \mathrm{M}), \mathrm{TPR}$, topiramate $(100 \mu \mathrm{M}), \mathrm{VPA}$, sodium valproate $(100 \mu \mathrm{M})$

irregular repeated epileptiform-like discharges as measured by EEG. cacnalaa LOF in larval zebrafish leads to mortality, even when individual splice variants are targeted. The cause of mortality may be attributable to defects in the brain, peripheral effects, or both. Peripheral effects of cacnalaa LOF $(2.5 \mathrm{ng}+2.5 \mathrm{ng})$ were evidenced by changes in morphology of morphants, i.e., slight hyperpigmentation, lack of swim bladder, and shorter body length - phenotypes also observed in other zebrafish models of epilepsy [22, 40]. Notably, cacnalaa mRNA in zebrafish embryos is maternally contributed [41, 42], possibly accounting for the higher mortality rate at $24 \mathrm{~h}$ than $4 \mathrm{~h}$ after injection. Saito et al. [43] revealed that knockdown of Cacnala to $28 \%$ of baseline $\mathrm{Ca}_{\mathrm{v}} 2.1$ induced severe ataxia, while reduction to $14 \%$ dramatically shortened the lifespan of mice. Similarly, conditional ablation of $\mathrm{Ca}_{\mathrm{v}} 2.1$ channels leading to Cacnala gene LOF in mice resulted in ataxia and dystonia starting at around postnatal days 10-12 and death at postnatal days 21-22 [44]. In our experimental setting, the cause of mortality is partially related to morphology abnormalities. However, lethal/deleterious effects on brain function cannot be ruled out, especially since our study was based on analyzing behavioral and EEG changes at lower, non-lethal doses of MOs.

The behavioral impairments observed in cacnala morphants indicate defects of neuronal origin. The decreased/absent reflex to the touch stimulus may depend on disruption of the spinal reflex mechanism since the touchevoked locomotor activity response allows assessment of muscle performance in zebrafish. Touch stimuli, e.g., touch of the zebrafish tail tip with a needle, results in muscle contraction accompanied with burst swim [45]. P/Q calcium channels in mammals are abundantly expressed in neuromuscular junctions where they control presynaptic acetylcholine release [46] and are considered to mediate fast neuromuscular neurotransmission also in zebrafish [47, 48]. To the best of our knowledge, cacnalaa expression in muscles and the spinal cord has not been investigated, but cacnalab, the paralog to cacnalaa, was proposed as a mediator of locomotor behavior and touch-evoked motor response as indicated in fakir mutants $[49,50]$. The high expression of cacnalab was found in sensory neurons, but MO knockdown of cacnalab disturbed touch-evoked activation of motor neurons, the third neuron of the reflex arc [50].

Although cacnalaa morphants did not inflate their swim bladder at $4 \mathrm{dpf}$, other reports have indicated that this defect does not necessarily interfere significantly with total distance traveled, but only affects slow movements associated with maintaining balance $[22,51]$. Thus, the lack of an inflated swim bladder can likely be ruled out as a cause for reduced locomotor activity.

Reduced locomotor activity in morphants was similar in both light and dark phases. It has been repeatedly demonstrated that abrupt switching from light to dark induces a rapid increase in locomotor activity of zebrafish larvae, which decreases to baseline after a few $(5-10)$ minutes $[51,52]$. A similar uniform reduction in motility may indicate the reduction of skeletal muscle reactivity or muscle relaxation due to decreased activity of $\mathrm{P} / \mathrm{Q}$ calcium channels [47, 48]. On the other hand, Samarut et al. [29] observed reduced locomotor activity in gabral $^{-1-}$ zebrafish mutants. Although rapid switching of light to dark induced a very quick and transient increase in their activity, this was followed by profound hypolocomotion [29].

In this study, we observed that spontaneous epileptiformlike events in the form of abrupt high-voltage spikes, spikewave complexes, and polyspike-wave discharges occurred in $92 \%$ of cacnalaa morphants. Previous studies indicated that chemicals (e.g., pentylentetrazole or allylglycine) $[37,39,53]$ as well as mutations in different genes (e.g., scn1lab, aldh7a1) $[22,24]$ increase locomotor activity in zebrafish larvae reminiscent of tonic-clonic-like seizures. Indeed, tonic-clonic-like seizures have been described both in genetic and pharmacological models of epilepsy in zebrafish [22, 54]. The number and frequency of EEG discharges correlated with behavioral outcome, i.e., a dramatic increase in locomotor activity with rapid "whirlpool-like" circling followed by loss of posture. cacnalaa morphants did not display this kind of behavior (thus ruling out tonic-clonic-like seizures), and the frequency of epileptiform-like discharges was lower than in all abovementioned models. Notably, our data are more in line with the phenotype reported for zebrafish $t \mathrm{sc}^{-/-}$mutants (model of tuberous sclerosis complex) [51], with regard to seizure duration and frequency. In this study however, the authors did not draw any final conclusion as to what type of seizures were observed in $\mathrm{sc}^{-/-}$mutants.

In humans and rodents, absence seizures occur as bilateral, synchronous slow-wave discharges (typically $3 \mathrm{~Hz}$ or $5-7 \mathrm{~Hz}$, respectively) $[12,17,19-21,55]$. Although we could not clearly distinguish this pattern of discharges in cacnalaa morphants, we cannot rule out that species differences may determine the EEG pattern of absence seizures in zebrafish.

Our study revealed that all four drugs recommended in the management of absence seizures significantly diminished the number of epileptiform-like events in 4-dpf 
cacnalaa morphants and were equally potent. Noteworthy, VPA did not affect mean and cumulative duration of events, with the tendency to even increase the latter. Interestingly, the International League Against Epilepsy (ILAE) guidelines recommend VPA as the drug of choice for the treatment of absence epilepsy (class I) in children [56]. On the other hand, we observed that TPR was equally potent when compared with ETX, a class I-indicated drug for absence seizures. Although, ILAE guidelines do not include recommendations for TPR, it is commonly used to treat absence seizures in humans as a second-choice therapy [57, 58]. LTG belongs to class III (i.e., possibly effective) ASDs for absence seizures in patients. In our model, LTG significantly reduced the cumulative duration of EEG discharges and exhibited a tendency to decrease mean duration of events. In rodents with Cacnala LOF, both ETX and VPA efficacy were observed [17, 18, 59] with less consistent data for other drugs, i.e., LTG and TPR [60, 61]. ETX also decreased the incidence of EEG discharges in WAG/ Rij rats [62-64]. Nevertheless, taking our data into consideration, it is possible that differences in ASD modes of action might account for differences in our observations. ETX is believed to selectively inhibit T-type calcium channels, while VPA has broader spectrum activity and apart from calcium channel inhibition, also exerts its effect through sodium channel inhibition and activation of GABA-ergic neurotransmission. LTG is a broadspectrum blocker of calcium and sodium channels, increasing GABA levels, while TPR additionally increases the affinity of GABA to $\mathrm{GABA}_{\mathrm{A}}$ receptors (for review see [65]). CBZ, also a sodium channel blocker, did not affect the number of EEG discharges in cacnalaa morphants. It was reported that CBZ might exaggerate absence seizures in Cacnala mutation carriers, both in humans and rodents $[66,67]$. Similarly, CBZ exaggerated the incidence of EEG discharges in WAG/Rij rats [63]. On the other hand, phenytoin, another sodium channel blocker, did not affect seizure incidence in Cacnal a models of absence seizures [17, 18, 59]. Although, CBZ did not increase the number of EEG discharges in cacnalaa morphants, it cannot be excluded that the time of incubation ( $2 \mathrm{~h}$ ) was not long enough to enhance EEG discharges.

In summary, our study describes for the first time, the phenotypic profile of reduced cacnalaa function in larval zebrafish, which causes significant locomotor impairment and even lethality. The described behavioral phenotype is accompanied by irregular, repeated epileptiform-like discharges as recorded by EEG. In addition, the pharmacological profiling data further support the validation of this new model for the study of absence seizures. Given that absence epilepsy is most common in children, the use of a developmental model such as the zebrafish allows for the study of epileptogenesis mechanisms (e.g., observed differences in cortical interneuron populations) [68] in the brain at relevant life stages when absence seizures are most likely to occur. Our analysis of the cacnalaa LOF in zebrafish was performed at $4 \mathrm{dpf}$, which is equivalent to 3 months post-birth in humans. This larval zebrafish model is also amenable to large-scale drug screening, opening up the possibility for the discovery of new therapeutic compounds to treat the $30 \%$ of absence epilepsy patients that are drug resistant. Furthermore, although absence epilepsy is categorized as a relatively benign form of epilepsy compared with other genetic generalized epilepsy syndromes, it is still often accompanied by comorbidities that can persist even after seizure freedom is achieved. Moreover, drugs used to treat absence epilepsy, such as ETX and VPA, are often not well tolerated or are ineffective. Thus, this zebrafish model can also be used to test for potential disease-modifying activity of drugs with regard to effective treatment of comorbidities (e.g., learning and memory deficits, attention deficit hyperactivity disorder, and anxiety) associated with absence epilepsy.

Funding Information KG received a mobility grant from the Polish Ministry of Science and Higher Education within the "Mobilność Plus V" program (decision nr 1649/1/MOB/V/17/2018/0; 01.01.201831.12.2018). KG has received funding from the European Union's Horizon 2020 research and innovation program under the Marie Skłodowska-Curie (grant agreement no. 798703-GEMZ-H2020MSCA-IF-2017). This work was partially supported by start-up funds from the Centre for Molecular Medicine Norway (for CVE) and the Research Council of Norway through its Centres of Excellence funding scheme (project number 262652) and FRIPRO grant (project number 221831 for BJM and AS).

Compliance with Ethical Standards All experiments were approved by the Norwegian Food Safety Authority experimental animal administration's supervisory and application system (FOTS-18/106800-1).

Conflict of Interest The authors declare that they have no conflict of interest.

Open Access This article is licensed under a Creative Commons Attribution 4.0 International License, which permits use, sharing, adaptation, distribution and reproduction in any medium or format, as long as you give appropriate credit to the original author(s) and the source, provide a link to the Creative Commons licence, and indicate if changes were made. The images or other third party material in this article are included in the article's Creative Commons licence, unless indicated otherwise in a credit line to the material. If material is not included in the article's Creative Commons licence and your intended use is not permitted by statutory regulation or exceeds the permitted use, you will need to obtain permission directly from the copyright holder. To view a copy of this licence, visit http://creativecommons.org/licenses/by/4.0/.

\section{References}

1. Heyes S, Pratt WS, Rees E, Dahimene S, Ferron L, Owen MJ, Dolphin AC (2015) Genetic disruption of voltage-gated calcium channels in psychiatric and neurological disorders. Prog Neurobiol 134:36-54. https://doi.org/10.1016/j.pneurobio.2015.09.002

2. Hillman D, Chen S, Aung TT, Cherksey B, Sugimori M, Llinás RR (1991) Localization of P-type calcium channels in the central nervous system. Proc Natl Acad Sci U S A 88:7076-7080. https://doi. org/10.1073/pnas.88.16.7076 
3. Takahashi T, Momiyama A (1993) Different types of calcium channels mediate central synaptic transmission. Nature 366:156-158. https://doi.org/10.1038/366156a0

4. Volsen SG, Day NC, McCormack AL et al (1995) The expression of neuronal voltage-dependent calcium channels in human cerebellum. Mol Brain Res 34:271-282. https://doi.org/10.1016/0169328X(95)00234-J

5. Westenbroek RE, Sakurai T, Elliott EM, Hell JW, Starr TV, Snutch TP, Catterall WA (1995) Immunochemical identification and subcellular distribution of the alpha 1A subunits of brain calcium channels. J Neurosci 15:6403-6418

6. Igelmund P, Zhao YQ, Heinemann U (1996) Effects of T-type, Ltype, N-type, P-type, and Q-type calcium channel blockers on stimulus-induced pre- and postsynaptic calcium fluxes in rat hippocampal slices. Exp Brain Res 109:22-32. https://doi.org/10.1007/ bf00228623

7. Rossignol E, Kruglikov I, van den Maagdenberg AMJM, Rudy B, Fishell G (2013) CaV 2.1 ablation in cortical interneurons selectively impairs fast-spiking basket cells and causes generalized seizures. Ann Neurol 74:209-222. https://doi.org/10.1002/ ana.23913

8. Jen JC, Wan J (2018) Episodic ataxias. Handb Clin Neurol 155: 205-215. https://doi.org/10.1016/B978-0-444-64189-2.00013-5

9. Damaj L, Lupien-Meilleur A, Lortie A, Riou É, Ospina LH, Gagnon L, Vanasse C, Rossignol E (2015) CACNA1A haploinsufficiency causes cognitive impairment, autism and epileptic encephalopathy with mild cerebellar symptoms. Eur J Hum Genet 23:1505-1512. https://doi.org/10.1038/ejhg.2015.21

10. Reinson K, Õiglane-Shlik E, Talvik I, Vaher U, Õunapuu A, Ennok M, Teek R, Pajusalu S et al (2016) Biallelic CACNA1A mutations cause early onset epileptic encephalopathy with progressive cerebral, cerebellar, and optic nerve atrophy. Am J Med Genet A 170: 2173-2176. https://doi.org/10.1002/ajmg.a.37678

11. Balck A, Hanssen H, Hellenbroich Y, Lohmann K, Münchau A (2017) Adult-onset ataxia or developmental disorder with seizures: two sides of missense changes in CACNA1A. J Neurol 264:1520 1522. https://doi.org/10.1007/s00415-017-8494-z

12. Du X, Chen Y, Zhao Y et al (2017) Dramatic response to pyridoxine in a girl with absence epilepsy with ataxia caused by a de novo CACNA1A mutation. Seizure - European Journal of Epilepsy 45: 189-191. https://doi.org/10.1016/j.seizure.2016.12.020

13. Lee CG, Lee J, Lee M (2018) Multi-gene panel testing in Korean patients with common genetic generalized epilepsy syndromes. PLoS One:13. https://doi.org/10.1371/journal.pone.0199321

14. Lv Y, Wang Z, Liu C, Cui L (2017) Identification of a novel CACNA1A mutation in a Chinese family with autosomal recessive progressive myoclonic epilepsy. Neuropsychiatr Dis Treat 13: 2631-2636. https://doi.org/10.2147/NDT.S145774

15. Choi K-D, Kim J-S, Kim H-J, Jung I, Jeong SH, Lee SH, Kim DU, Kim SH et al (2017) Genetic variants associated with episodic ataxia in Korea. Sci Rep 7:1-11. https://doi.org/10.1038/s41598-01714254-7

16. Epi4K Consortium (2016) De novo mutations in SLC1A2 and CACNA1A are important causes of epileptic encephalopathies. Am J Hum Genet 99:287-298. https://doi.org/10.1016/j.ajhg.2016.06.003

17. Kim TY, Maki T, Zhou Y, Sakai K, Mizuno Y, Ishikawa A, Tanaka R, Niimi K et al (2015) Absence-like seizures and their pharmacological profile in tottering-6j mice. Biochem Biophys Res Commun 463:148-153. https://doi.org/10.1016/j.bbrc.2015.05.050

18. Tokuda S, Kuramoto T, Tanaka K, Kaneko S, Takeuchi IK, Sasa M, Serikawa T (2007) The ataxic groggy rat has a missense mutation in the P/Q-type voltage-gated $\mathrm{Ca} 2+$ channel alpha1A subunit gene and exhibits absence seizures. Brain Res 1133:168-177. https:// doi.org/10.1016/j.brainres.2006.10.086
19. Zwingman TA, Neumann PE, Noebels JL, Herrup K (2001) Rocker is a new variant of the voltage-dependent calcium channel gene Cacnala. J Neurosci 21:1169-1178

20. Imbrici P, Jaffe SL, Eunson LH, Davies NP, Herd C, Robertson R, Kullmann DM, Hanna MG (2004) Dysfunction of the brain calcium channel CaV2.1 in absence epilepsy and episodic ataxia. Brain 127: 2682-2692. https://doi.org/10.1093/brain/awh301

21. Jouvenceau A, Eunson LH, Spauschus A, Ramesh V, Zuberi SM, Kullmann DM, Hanna MG (2001) Human epilepsy associated with dysfunction of the brain P/Q-type calcium channel. Lancet 358: 801-807. https://doi.org/10.1016/S0140-6736(01)05971-2

22. Zhang Y, Kecskés A, Copmans D, Langlois M, Crawford AD, Ceulemans B, Lagae L, de Witte PA et al (2015) Pharmacological characterization of an antisense knockdown zebrafish model of Dravet syndrome: inhibition of epileptic seizures by the serotonin agonist fenfluramine. PLoS One 10:e0125898. https://doi.org/10. 1371/journal.pone. 0125898

23. Brenet A, Hassan-Abdi R, Somkhit J et al (2019) Defective excitatory/inhibitory synaptic balance and increased neuron apoptosis in a zebrafish model of Dravet syndrome. Cells:8. https:// doi.org/10.3390/cells8101199

24. Pena IA, Roussel Y, Daniel K, Mongeon K, Johnstone D, Weinschutz Mendes H, Bosma M, Saxena V et al (2017) Pyridoxine-dependent epilepsy in zebrafish caused by Aldh7a1 deficiency. Genetics 207:1501-1518. https://doi.org/10.1534/ genetics.117.300137

25. Zabinyakov N, Bullivant G, Cao F, Fernandez Ojeda M, Jia ZP, Wen XY, Dowling JJ, Salomons GS et al (2017) Characterization of the first knock-out aldh7a1 zebrafish model for pyridoxinedependent epilepsy using CRISPR-Cas9 technology. PLoS One 12:e186645. https://doi.org/10.1371/journal.pone.0186645

26. de Calbiac H, Dabacan A, Marsan E, Tostivint H, Devienne G, Ishida S, Leguern E, Baulac S et al (2018) Depdc5 knockdown causes mTOR-dependent motor hyperactivity in zebrafish. Ann Clin Transl Neurol 5:510-523. https://doi.org/10.1002/acn3.542

27. Suls A, Jaehn JA, Kecskés A, Weber Y, Weckhuysen S, Craiu DC, Siekierska A, Djémié T et al (2013) De novo loss-of-function mutations in CHD2 cause a fever-sensitive myoclonic epileptic encephalopathy sharing features with Dravet syndrome. Am J Hum Genet 93:967-975. https://doi.org/10.1016/j.ajhg.2013.09.017

28. Galizia EC, Myers CT, Leu C, de Kovel CG, Afrikanova T, Cordero-Maldonado ML, Martins TG, Jacmin M et al (2015) CHD2 variants are a risk factor for photosensitivity in epilepsy. Brain 138:1198-1207. https://doi.org/10.1093/brain/awv052

29. Samarut É, Swaminathan A, Riché R, Liao M, Hassan-Abdi R, Renault S, Allard M, Dufour L et al (2018) $\gamma$-aminobutyric acid receptor alpha 1 subunit loss of function causes genetic generalized epilepsy by impairing inhibitory network neurodevelopment. Epilepsia 59:2061-2074. https://doi.org/10.1111/epi.14576

30. Baraban SC, Dinday MT, Hortopan GA (2013) Drug screening in Scnla zebrafish mutant identifies clemizole as a potential Dravet syndrome treatment. Nat Commun 4:2410. https://doi.org/10.1038/ ncomms 3410

31. Sourbron J, Partoens M, Scheldeman C, Zhang Y, Lagae L, de Witte P (2019) Drug repurposing for Dravet syndrome in scn1Lab-/- mutant zebrafish. Epilepsia 60:e8-e13. https://doi. org/10.1111/epi.14647

32. Stewart AM, Braubach O, Spitsbergen J, Gerlai R, Kalueff AV (2014) Zebrafish models for translational neuroscience research: from tank to bedside. Trends Neurosci 37:264-278. https://doi. org/10.1016/j.tins.2014.02.011

33. Howe K, Clark MD, Torroja CF, Torrance J, Berthelot C, Muffato M, Collins JE, Humphray S et al (2013) The zebrafish reference genome sequence and its relationship to the human genome. Nature 496:498-503. https://doi.org/10.1038/nature12111 
34. Novak AE, Jost MC, Lu Y, Taylor AD, Zakon HH, Ribera AB (2006) Gene duplications and evolution of vertebrate voltagegated sodium channels. J Mol Evol 63:208-221. https://doi.org/ 10.1007/s00239-005-0287-9

35. Russo E, Citraro R (2018) Pharmacology of epileptogenesis and related comorbidities in the WAG/Rij rat model of genetic absence epilepsy. J Neurosci Methods 310:54-62. https://doi.org/10.1016/j. jneumeth.2018.05.020

36. Proft J, Rzhepetskyy Y, Lazniewska J, et al (2017) The Cacnalh mutation in the GAERS model of absence epilepsy enhances T-type Ca2+ currents by altering calnexin-dependent trafficking of Cav3.2 channels. Sci rep 7:. doi: https://doi.org/10.1038/s41598-017-11591-5

37. Afrikanova T, Serruys A-SK, Buenafe OEM et al (2013) Validation of the zebrafish pentylenetetrazol seizure model: locomotor versus electrographic responses to antiepileptic drugs. PLoS One 8: e54166. https://doi.org/10.1371/journal.pone.0054166

38. Thisse C, Thisse B (2008) High-resolution in situ hybridization to whole-mount zebrafish embryos. Nat Protoc 3:59-69. https://doi. org/10.1038/nprot.2007.514

39. Nieoczym D, Socała K, Gawel K, Esguerra CV, Wyska E, Wlaź P (2019) Anticonvulsant activity of pterostilbene in zebrafish and mouse acute seizure tests. Neurochem Res 44:1043-1055. https:// doi.org/10.1007/s11064-019-02735-2

40. Grone BP, Marchese M, Hamling KR, Kumar MG, Krasniak CS, Sicca F, Santorelli FM, Patel M et al (2016) Epilepsy, behavioral abnormalities, and physiological comorbidities in syntaxin-binding protein 1 (STXBP1) mutant zebrafish. PLoS One 11:e0151148. https://doi.org/10.1371/journal.pone.0151148

41. Bouleau A, Desvignes T, Traverso JM et al (2014) Maternally inherited npm2 mRNA is crucial for egg developmental competence in zebrafish. Biol Reprod 91:43. https://doi.org/10.1095/ biolreprod.114.119925

42. Popgeorgiev N, Bonneau B, Gillet JP et al (2018) Control of programmed cell death during zebrafish embryonic development. Recent Advances in Zebrafish Researches. https://doi.org/10. 5772/intechopen.74494

43. Saito H, Okada M, Miki T et al (2009) Knockdown of Cav2.1 calcium channels is sufficient to induce neurological disorders observed in natural occurring Cacnala mutants in mice. Biochem Biophys Res Commun 390:1029-1033. https://doi.org/10.1016/j. bbrc.2009.10.102

44. Todorov B, van de Ven RCG, Kaja S et al (2006) Conditional inactivation of the Cacnala gene in transgenic mice. Genesis 44 : 589-594. https://doi.org/10.1002/dvg.20255

45. Sztal TE, Ruparelia AA, Williams C, Bryson-Richardson RJ (2016) Using touch-evoked response and locomotion assays to assess muscle performance and function in zebrafish. J Vis Exp. https://doi. org/10.3791/54431

46. Uchitel OD, Protti DA, Sanchez V, Cherksey BD, Sugimori M, Llinás R (1992) P-type voltage-dependent calcium channel mediates presynaptic calcium influx and transmitter release in mammalian synapses. Proc Natl Acad Sci U S A 89:3330-3333. https://doi. org/10.1073/pnas.89.8.3330

47. Naranjo D, Wen H, Brehm P (2015) Zebrafish CaV2.1 calcium channels are tailored for fast synchronous neuromuscular transmission. Biophys J 108:578-584. https://doi.org/10.1016/j.bpj.2014.11.3484

48. Wen H, Linhoff MW, Hubbard JM, Nelson NR, Stensland D, Dallman J, Mandel G, Brehm P (2013) Zebrafish calls for reinterpretation for the roles of $\mathrm{P} / \mathrm{Q}$ calcium channels in neuromuscular transmission. J Neurosci 33:7384-7392. https://doi.org/10.1523/ JNEUROSCI.5839-12.2013

49. Granato M, van Eeden FJ, Schach U, Trowe T, Brand M, FurutaniSeiki M, Haffter P, Hammerschmidt M et al (1996) Genes controlling and mediating locomotion behavior of the zebrafish embryo and larva. Development 123:399-413
50. Low SE, Woods IG, Lachance M, Ryan J, Schier AF, Saint-Amant L (2012) Touch responsiveness in zebrafish requires voltage-gated calcium channel 2.1b. J Neurophysiol 108:148-159. https://doi.org/ 10.1152/jn.00839.2011

51. Scheldeman C, Mills JD, Siekierska A et al (2017) mTOR-related neuropathology in mutant tsc2 zebrafish: phenotypic, transcriptomic and pharmacological analysis. Neurobiol Dis 108: 225-237. https://doi.org/10.1016/j.nbd.2017.09.004

52. Burgess HA, Granato M (2007) Modulation of locomotor activity in larval zebrafish during light adaptation. J Exp Biol 210:25262539. https://doi.org/10.1242/jeb.003939

53. Leclercq K, Afrikanova T, Langlois M, de Prins A, Buenafe OE, Rospo CC, van Eeckhaut A, de Witte PA et al (2015) Cross-species pharmacological characterization of the allylglycine seizure model in mice and larval zebrafish. Epilepsy Behav 45:53-63. https://doi. org/10.1016/j.yebeh.2015.03.019

54. Baraban SC, Taylor MR, Castro PA, Baier H (2005) Pentylenetetrazole induced changes in zebrafish behavior, neural activity and c-fos expression. Neuroscience 131:759-768. https:// doi.org/10.1016/j.neuroscience.2004.11.031

55. Depaulis A, David O, Charpier S (2016) The genetic absence epilepsy rat from Strasbourg as a model to decipher the neuronal and network mechanisms of generalized idiopathic epilepsies. J Neurosci Methods 260:159-174. https://doi.org/10.1016/j. jneumeth.2015.05.022

56. Glauser T, Ben-Menachem E, Bourgeois B, Cnaan A, Guerreiro C, Kälviäinen R, Mattson R, French JA et al (2013) Updated ILAE evidence review of antiepileptic drug efficacy and effectiveness as initial monotherapy for epileptic seizures and syndromes. Epilepsia 54:551-563. https://doi.org/10.1111/epi.12074

57. Cross JH (2002) Topiramate monotherapy for childhood absence seizures: an open label pilot study. Seizure 11:406-410

58. Faught E (2007) Topiramate in the treatment of partial and generalized epilepsy. Neuropsychiatr Dis Treat 3:811-821. https://doi. org/10.2147/ndt.s512

59. Heller AH, Dichter MA, Sidman RL (1983) Anticonvulsant sensitivity of absence seizures in the tottering mutant mouse. Epilepsia $24: 25-34$

60. Nakamura J, Tamura S, Kanda T, Ishii A, Ishihara K, Serikawa T, Yamada J, Sasa M (1994) Inhibition by topiramate of seizures in spontaneously epileptic rats and DBA/2 mice. Eur J Pharmacol 254: 83-89. https://doi.org/10.1016/0014-2999(94)90373-5

61. Hosford DA, Wang Y (1997) Utility of the lethargic (lh/lh) mouse model of absence seizures in predicting the effects of lamotrigine, vigabatrin, tiagabine, gabapentin, and topiramate against human absence seizures. Epilepsia 38:408-414

62. Sarkisova KY, Kuznetsova GD, Kulikov MA, van Luijtelaar G (2010) Spike-wave discharges are necessary for the expression of behavioral depression-like symptoms. Epilepsia 51:146-160. https://doi.org/10.1111/j.1528-1167.2009.02260.x

63. Russo E, Citraro R, Scicchitano F, de Fazio S, Perrotta I, di Paola ED, Constanti A, de Sarro G (2011) Effects of early long-term treatment with antiepileptic drugs on development of seizures and depressive-like behavior in a rat genetic absence epilepsy model. Epilepsia 52:1341-1350. https://doi.org/10.1111/j.1528-1167. 2011.03112.x

64. Blumenfeld H, Klein JP, Schridde U, Vestal M, Rice T, Khera DS, Bashyal C, Giblin K et al (2008) Early treatment suppresses the development of spike-wave epilepsy in a rat model. Epilepsia 49: 400-409. https://doi.org/10.1111/j.1528-1167.2007.01458.x

65. Lasoń W, Dudra-Jastrzębska M, Rejdak K, Czuczwar SJ (2011) Basic mechanisms of antiepileptic drugs and their pharmacokinetic/pharmacodynamic interactions: an update. Pharmacol Rep 63:271-292

66. Liu L, Zheng T, Morris MJ, Wallengren C, Clarke AL, Reid CA, Petrou S, O'Brien TJ (2006) The mechanism of carbamazepine 
aggravation of absence seizures. J Pharmacol Exp Ther 319:790 798. https://doi.org/10.1124/jpet.106.104968

67. Parker AP, Agathonikou A, Robinson RO, Panayiotopoulos CP (1998) Inappropriate use of carbamazepine and vigabatrin in typical absence seizures. Dev Med Child Neurol 40:517-519
68. Studer F, Laghouati E, Jarre G, David O, Pouyatos B, Depaulis A (2019) Sensory coding is impaired in rat absence epilepsy. J Physiol Lond 597:951-966. https://doi.org/10.1113/JP277297

Publisher's Note Springer Nature remains neutral with regard to jurisdictional claims in published maps and institutional affiliations. 